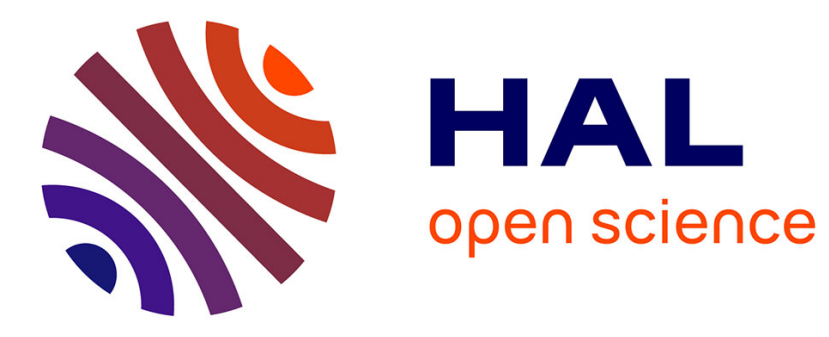

\title{
Dupuytren's Disease and exposure to vibration: Systematic review and Meta-analysis
}

Sylvain Mathieu, Geraldine Naughton, Alexis Descatha, Martin Soubrier, Fréderic Dutheil

\section{- To cite this version:}

Sylvain Mathieu, Geraldine Naughton, Alexis Descatha, Martin Soubrier, Fréderic Dutheil. Dupuytren's Disease and exposure to vibration: Systematic review and Meta-analysis. Joint Bone Spine, 2020, 87 (3), pp.203-207. 10.1016/j.jbspin.2020.02.001 . hal-02496446

\section{HAL Id: hal-02496446 \\ https://univ-angers.hal.science/hal-02496446}

Submitted on 1 Apr 2020

HAL is a multi-disciplinary open access archive for the deposit and dissemination of scientific research documents, whether they are published or not. The documents may come from teaching and research institutions in France or abroad, or from public or private research centers.
L'archive ouverte pluridisciplinaire HAL, est destinée au dépôt et à la diffusion de documents scientifiques de niveau recherche, publiés ou non, émanant des établissements d'enseignement et de recherche français ou étrangers, des laboratoires publics ou privés. 


\section{Dupuytren's Disease and exposure to vibration: systematic review and Meta-analysis}

Sylvain Mathieu ${ }^{1}$, Geraldine Naughton $^{2}$, Alexis Descatha ${ }^{3}$, Martin Soubrier ${ }^{1}$, Frédéric Dutheil ${ }^{4}$

1. Service de Rhumatologie. CHU Clermont-Ferrand. Université Clermont Auvergne. France

2. Department of Educational Studies, Macquarie University, Sydney, New South Wales, Australia, and the Department of Health and Medical Sciences, Swinburne University of Technology, Melbourne, Australia

3. Univ Angers, UMR_S1085, CHU Angers, Univ Rennes, Inserm, EHESP, Irset (Institut de recherche en santé, environnement et travail), Angers, France. UVSQ, U1168 (VIMA: Aging and chronic diseases. Epidemiological and public health approaches), UMS 011 (Populationbased Epidemiologic Cohorts Unit), Versailles St-Quentin Univ, Paris Sud Univ, Paris Saclay Univ, Inserm, Villejuif, France

4. CNRS, LaPSCo, Physiological and Psychosocial Stress, CHU Clermont-Ferrand, University Hospital of Clermont-Ferrand, Occupational and Preventive Medicine, WittyFit, Université Clermont Auvergne, Clermont-Ferrand, France

Corresponding author: Dr Sylvain Mathieu.

e-mail address: smathieu@ chu-clermontferrand.fr 


\section{Abstract}

Introduction: Dupuytren's Disease (DD) occurs frequently in the entire population. Several risk factors are well known, including diabetes, alcohol, and age. In this meta-analysis, we assessed the role of occupational vibration exposure in the risk of DD, an issue currently under debate. Methods: We searched PubMed, Google Scholar, and the Cochrane Library to find references up to June 2019. DD prevalence was calculated using meta-proportion analysis. Differences in characteristics between DD patients and controls were expressed as standardized mean differences using the inverse of variance method or percentages using also meta-proportion analysis. We performed meta-regression analyses to assess the effects of alcohol, smoking, age, and sex on the DD incidence for the patients with DD that were exposed to vibrations.

Results: We included 9 studies, comprising a total of 60,570 patients, including 1,804 DD patients. Prevalence of DD was 9.8\% (95\%CI:5.9-14.4\%). Compared with controls, patients with DD were older, more diabetic, more smokers and with a higher consumption of alcohol. Meta-analysis of the nine longitudinal studies comparing DD occurrence between patients exposed to vibration $(626$ of 6,825$)$ or not $(1,220$ of 52,502$)$ revealed a significantly increased DD incidence among patients with vibration exposure compared with controls $(\mathrm{OR}=2.87$; 95\%CI:1.41-5.84). In metaregression we found no significant influence of all parameters on DD.

Conclusion: Age and environmental factors had no effect on DD prevalence among patients exposed to vibrations, despite a $10 \%$ prevalence in this group. Using vibration tools at work should be recognized as an important risk factor of developing DD.

Key-words: Dupuytren disease, work, vibration exposure, meta-analysis

\section{Introduction}

Dupuytren's disease (DD), characterised by contracture of the fourth and fifth fingers of the hand, is a common disease that affects $7 \%$ of the population in the USA and Iceland and 
up to $17 \%$ of the populations in other countries (1-3). Currently, the low number of studies on DD are insufficient to provide a realistic prevalence, particularly in France. Some patients are completely asymptomatic, but contracture of the fingers could cause pain, esthetic discomfort and functional disability (4). However, patients tend not to talk about it spontaneously to their medical doctor because DD is considered to be benign and banal and sometimes shameful because it is often related to the consumption of alcohol. The relation between alcohol consumption and development of DD is real and well-known. However, alcohol is not the only one risk factor of DD. DD has a clear genetic predisposition (5). The familial incidence was clearly higher and has been reported to be $44 \%$ and $74 \%$ in populations from Sweden and Iceland. The exact pathogenesis of DD remains to be elucidated but there are recent advances in its understanding (6). The impact of work on the occurrence of DD remains controversial. Biomechanical work exposure, such as vibration exposure, has been reported to increase the risk of DD $(7,8)$ but some authors still conclude that the use of vibration tools at work is not a risk factor of DD $(9,10)$.

A meta-analysis addressed the uncertainty surrounding the exposure to occupational vibration and the risk of contracting Dupuytren's contracture (8). Five studies directly on occupational vibration met the authors' rigorous selection and quality reporting criteria. Their results were divided into studies with and without success in meeting the quality reporting criteria. The meta Odds Ratio (OR) for studies on vibration was 2.88 (95\%CI 1.36- 6.07) but when the quality reporting criteria was applied to the studies, the meta OR was reduced to 2.14 (95\% CI $1.59-2.88$. Discussion of meta-analysis results included criticisms of more crosssectional than cohort studies, inconsistent ages and criteria for control groups, again inconsistent or quasi designed questions around potential confounders, measures of exposure lacking precision and studies omitting the use of clinical assessment as a gold standard for the diagnosis of Dupuytren's contracture. However, since this meta-anlaysis in 2011, a number of 
larger, representative and well considered studies on the relative risks of Dupuytren's contracture in occupational vibration workers have been published.

Therefore, the purpose of this systematic review and meta-analysis is to update and strengthen the existing evidence addressing the risk of Dupuytren's contracture for workers with high cumulative exposure to hand operated vibration devices.

\section{Methods}

\section{Literature search}

We searched PubMed, Google Scholar and the Cochrane Central Register of Controlled Trials to identify all reports of interest published in English or French up to June $6^{\text {th }}, 2019$. The following search terms were used in PubMed: “(Fibromatosis OR Dupuytren) AND (vibration OR work)". We did not used any limits to obtain a maximum of references that were thereafter included in analysis or excluded according to the reasons explained in the section "Trail selection".

We also performed a manual search of the references of identified articles. Finally, we collected data from the electronic abstract databases of the annual scientific meetings of the French Society of Rheumatology congress, the European League Against Rheumatism (EULAR) congress, and the American College of Rheumatology from 2007-2019 using the following terms: "Dupuytren". We included all case-control studies considering exposure of vibration and risk of Dupuytren's Disease (DD) development.

\section{Trial selection}

One author (SM) identified potentially relevant articles by reading the title, keywords, and abstract first. After this first step of selection, he read the full-text article. The exclusion criteria were commentary, meta-analysis or discussion papers, case reports and studies including fewer than five patients, lack of data about vibration exposure, not Dupuytren's Disease patients, full text not available, and data not usable for statistical analysis (i.e., lacking 
SD or interquartile range). In the same study, there may be different cohorts of DD patients and thereafter the study was included twice.

Quality of the included articles was assessed using SIGN checklist (https://www.sign.ac.uk/methodology.html).

\section{Data extraction}

Data extraction was performed by one author (SM). From case-control studies, we recorded the number of patients exposed to vibration and the number of patients with DD. When job information was available, we also recorded the type of job that exposed the workers to vibration and the kind of vibration tools used. Moreover, when available, we recorded information on whether exposure to vibrations occurred outside of work (i.e., during leisure activities, long distance driving, do-it-yourself projects). Extracted data were checked and confirmed by another author (GN) who read the full-text article again and was blinded to data extracted by SM. In case of difference between data, full-text was read a third time and consensus was obtained.

When we identified articles written by the same author (for example, Descatha authored 4 of the 10 reported studies), we checked whether the patients included belonged to the same or a different cohort from those included in other studies. In case of patients belonged to the same cohort, they were only included once.

\section{Statistical analysis}

Continuous variables were expressed as the weighted mean $\pm \mathrm{SD}$. We calculated the DD prevalence by performing meta-analysis of proportions (inverse of variance method).

Differences between DD patients and controls were expressed as the standardized mean difference for continuous variables using the inverse of variance method-with $0.2-0.8$ indicating a moderate differences and $>0.8$ a large differences or comparison of prevalence for dichotomous variables. The Mantel-Haenszel procedure was used to determine the odds ratio 
(OR) of DD in patients with vibration exposure versus controls in case controlled studies. This method provided a common OR estimate and $95 \%$ confidence interval (CI). The statistical heterogeneity between results was assessed using $\mathrm{I}^{2}$, which is easy to interpret and is the most common metric for measuring the magnitude of between-study heterogeneity. $\mathrm{I}^{2}$ values range between $0-100 \%$, with $<25 \%$ typically considered low, $25-50 \%$ modest, and $>50 \%$ high (ref Higgins BMJ 2003; 327:557-60). Using this statistical method, we generally assumed the presence of heterogeneity when the $P$ value of the $\mathrm{I}^{2}$ test was $<0.05$. In cases of heterogeneity, we used random-effects models; otherwise, we used a fixed-effects model.

We conducted a meta-regression to assess effects of other parameters such as alcohol, smoking, age or sex on the risk of developing DD in case of vibration exposure. Statistical analyses were conducted using Review Manager Software, version 5.0 (Cochrane).

\section{Results}

Searching the databases yielded a total of 282 citations. After reading the title, abstract, and full text, we eliminated all but 9 eligible studies (figure 1).

We therefore included 9 studies, comprising a total of 60,570 patients, including 1,804 DD patients (Table 1). We found that 6,825 patients had been exposed to vibrations. Information about the job or the kind of tools used was often lacking. When it was reported, the jobs included stonecarving, quarry drilling, mining, and digging; and the tools used were shovels, chippers, or grinders. Exposure to vibrations outside of work was never reported in the included manuscripts. Prevalence of DD in these 9 studies was 9.8\% (95\% CI: $5.9-14.4 \%$ ). Compared with the 58,766 controls, patients with DD were older $(52.4 \pm 7.7$ vs $42.1 \pm 9.3$ years $\mathrm{p}<0.001)$, were more often diabetic $(11.4 \%$ (95\% CI: $6.8-17.1 \%)$ vs. $5.5 \%$ (95\% CI: 1.5 $11.9 \%) ; \mathrm{p}=0.004)$ and had a higher consumption of alcohol (48.6\% (95\% CI: 20.6-77.0\%) vs. 42.2\% (95\% CI: 14.4-73.2\%); $\mathrm{p}=0.04$ ). DD patients were more smokers than controls but 
difference did not reach statistical significance (41.7\% (95\% CI: $26.9-57.3 \%)$ vs. $38.4 \%$ (95\% CI: $25.6-52.1 \%) ; \mathrm{p}=0.25)$.

Meta-analysis of the nine longitudinal studies comparing DD occurrence between patients exposed to vibration $(626$ of 6,825$)$ or not $(1,220$ of 52,502$)$ revealed a significantly increased DD incidence among patients with vibration exposure compared with controls $(\mathrm{OR}=2.87 ; 95 \%$ CI: 1.41-5.84) (Figure 2). Sensitivity analyses showed same results after exclusion of studies with results outside of the funnel plot (one study excluded). Among the 10 studies included, 4 studies were written by the same author. Therefore, we decided to check whether the mean OR of those 4 studies pointed in the same direction as the mean ORs in the six other studies. We found consistent data $(\mathrm{OR}=1.90 ; 95 \% \mathrm{CI}: 1.22-2.96$ in the 4 studies by Descatha and $\mathrm{OR}=2.76$; 95\%CI: $0.73-10.48$ in the 6 other studies). Similarly, the study by Chanut et al represented $67 \%$ of the controls that were not exposed to vibrations and only $3 \%$ of the patients that were exposed to vibration. We could not rule out that some patients with DD might have been missed in the control population. Figure S1 [Appendix A, See the supplementary material associated with this article online] shows the final OR after excluding the Chanut study; the mean Odds ratio without the Chanut's study was $1.79[1.27,2.53]$, versus $2.87[1.41,5.84]$ with that study.

Meta-regression found no significant influence of alcohol consumption, tobacco use, age and sex on the risk of DD in patients that were exposed to vibration (figure 3).

The SIGN criteria for the quality of reporting provided some cautions for interpretation of findings. For example, some of the studies reported limitations of selection bias by recruiting patients from surgical clinics (11), which may have included an extreme end of the condition. Response rates often failed to meet predicted numbers for statistical power. Clinicians were not always engaged in important diagnostic assessments (12), and if they were used clinicians were not always reported to be blinded to participants' exposure status (13). Despite some attempts to objectively and subjectively assess the intensity and duration of occupational exposure 
involving vibration, inconsistency in the measures of exposure challenge the collective power of meta analysis and regression. In contrast, studies often involved large and representative samples, targeted relevant working populations with multiple years of exposure and there is increasing evidence of advanced comprehensive statistical investigations.

\section{Discussion}

Our meta-analysis found a higher risk of developing DD in patients using vibration tools at work with a 3 -fold higher risk compared with controls. In the 9 included studies, we found a prevalence of DD of $9.8 \%$ very close to the frequency reported in the literature. Frequency of DD is very different from one country to another and seems more important in Northern European countries such as a reported prevalence of $22.1 \%$ in The Netherlands (14).

Several studies in this review described some of the known risk factors of developing DD. Patients with DD were significantly older, more diabetic and had a higher consumption of alcohol. DD is more frequent in older patients $(15,16)$. Diabetes is an important risk factor of DD (17-18). The role of tobacco use in DD development is still debated (19). In this metaanalysis, patients with DD were more smokers but the difference with controls was not significant. Godtfredsen et al reported a clear association between smoking and DD (20). It was also reported a higher incidence of DD in men, white, hypertensive patients $(21,22)$. Perhaps because of heterogeneity across studies or insufficient statistical power however, the meta regression could not confirm these results.

The strongest finding in this meta-analysis is that vibration exposure at work should be considered as a risk factor of DD. Manual workers should be informed of the risk of developing DD. Several studies reported a relation between duration of vibration exposure and DD. Cocco et al (1987) found an increase the number of cases of DD and the number of years exposed to vibration (23). Similarly, a relation was evident between the risk of DD and intensity of 
vibration (24). Arguably, this association should not result in patients with DD being excluded or recognized as unfit for occupations exposed to vibration, but their other potential risk factors should be better controlled: smoking ceasation, alcohol consumption moderation or ceasation, and optimal control of diabetes.

Our present study has several limitations. Only 9 studies were included, which may seem insufficient to draw reliable conclusions. However, this still represents nearly 2000 patients with DD, which is not negligible. Another limitation is related to the publication bias-in that positive studies are more likely to be published than negative studies. We cannot exclude that some investigations have found no significant increase of DD in patients with manual work, but were never published or even submitted. However, we searched relevant abstracts in European and American congresses, and trial registries, such as PROSPERO (international prospective register of systematic reviews), and found no other references.

Our meta-analysis found a significant relation between vibration exposure and developement of DD. Manual workers should be informed of the risk of developing DD and other risk factors emerging in individual studies (smoking, alcohool intake, diabetes, hypertension) that should be investigated and controlled in this population.

\section{AUTHOR CONTRIBUTIONS}

All authors were involved in drafting this article or critically revising it for important intellectual content, and all authors approved the final version to be submitted for publication. Dr. Mathieu had full access to all of the study data, and takes responsibility for the data integrity and the accuracy of the data analysis.

Study conception and design. Mathieu, Dutheil, Soubrier

Acquisition of data. Mathieu, Naughton

Analysis and interpretation of data. Mathieu, Naughton, Dutheil, Soubrier FUNDING SOURCE ROLE 
There is no financial support for this research.

\section{DISCLOSURE OF INTEREST}

All the authors have no competing interest or conflict of interest.

Appendix A. Supplementary data

Supplementary data (Figure S1) associated with this article can be found in the online version at ... 


\section{REFERENCES}

1. Dibenedetti DB, Nguyen D, Zografos L, et al. Prevalence, incidence, and treatments of Dupuytren's disease in the United States: results from a population-based study. Hand (N Y). 2011 Jun;6(2):149-58.

2. Zerajic D, Finsen V. Dupuytren's disease in Bosnia and Herzegovina. An epidemiological study. BMC Musculoskelet Disord. 2004 Mar 29;5:10

3. Gudmundsson KG, Arngrímsson R, Sigfússon N, et al. Epidemiology of Dupuytren's disease: clinical, serological, and social assessment. The Reykjavik Study. J Clin Epidemiol. 2000 Mar 1;53(3):291-6

4. Beaudreuil J, Allard A, Zerkak D, et al. Unité Rhumatologique des Affections de la Main (URAM) scale: development and validation of a tool to assess Dupuytren's disease-specific disability. Arthritis Care Res (Hoboken). 2011 Oct;63(10):1448-55

5. Becker K, Tinschert S, Lienert A et al. The importance of genetic susceptibility in Dupuytren's disease. Clin Genet 2015;87:483

6. Layton T, Nanchahal J. Recent advances in the understanding of Dupuytren's disease. F1000Res. 2019 Feb 28;8

7. Liss GM, Stock SR. Can Dupuytren's contracture be work-related?: review of the evidence. Am J Ind Med 1996;29:521-32.,

8. Descatha A, Jauffret P, Chastang JF et al. Should we consider Dupuytren's contracture as work-related? A review and meta-analysis of an old debate. BMC Musculoskelet Disord 2011;12:96

9. Hindocha S, McGrouther DA, Bayat A. Epidemiological evaluation of Dupuytren's disease incidence and prevalence rates in relation to etiology. Hand (N Y). 2009 Sep;4(3):256-69. 
10. Hindocha S, John S, Stanley JK, et al. The heritability of Dupuytren's disease: familial aggregation and its clinical significance. J Hand Surg Am. 2006 Feb;31(2):204-10.

11. Haines A, Levis C, Goldsmith CH et al. Dupuytren's contracture and handwork: A casecontrol study. Am J Ind Med 2017;60:724-733

12. Descatha A, Carton M, Mediouni Z, et al. Association among work exposure, alcohol intake, smoking and Dupuytren's disease in a large cohort study (GAZEL). BMJ Open $2014 ; 29: 004214$

13. Bovenzi M. Hand-arm vibration syndrome and dose-response relation for vibration induced white finger among quarry drillers and stonecarvers. Italian Study Group on Physical Hazards in the Stone Industry. Occup Environ Med 1994 ;51 :603-11

14. Lanting R, van den Heuvel ER, Westerink B, et al. Prevalence of Dupuytren disease in The Netherlands. Plast Reconstr Surg 2013

15. Jurisić D, Ković I, Lulić I, et al. Dupuytren's disease characteristics in Primorskogoranska County, Croatia. Coll Anthropol 2008, 32:1209-13

16. Tajika T, Kobayashi T, Kaneko T, et al. Epidemiological study for personal risk factors and quality of life related to Dupuytren's disease in a mountain village of Japan. Orthop Sci 2014;19:64-70

17. Morelli I, Fraschini G, Banfi AE. Dupuytren's Disease: Predicting Factors and Associated Conditions. A Single Center Questionnaire-Based Case-Control Study. Arch Bone Jt Surg. 2017 Nov;5(6):384-393.

18. Broekstra DC, Groen H, Molenkamp S, et al. A Systematic Review and Meta-Analysis on the Strength and Consistency of the Associations between Dupuytren Disease and Diabetes Mellitus, Liver Disease, and Epilepsy. Plast Reconstr Surg. 2018 Mar;141(3):367e-379e 
19. Geoghegan JM, Clark DI, Bainbridge LC et al. Risk factors in carpal tunnel syndrome. J Hand Surg Br. 2004 Aug;29(4):315-20.

20. Godtfredsen NS, Lucht H, Prescott E, et al. A prospective study linked both alcohol and tobacco to Dupuytren's disease. Clin Epidemiol 2004;57:858-63

21. Mansur HG, Oliveira ER, Gonçalves CB. Epidemiological analysis of patients with Dupuytren's disease. Rev Bras Ortop. 2017 Dec 14;53(1):10-14.

22. Mitra A. Goldstein RY. Dupuytren's contracture in the black population: a review. Ann Plast Surg 1994;32:619-22

23. Cocco PL, Frau P, Rapallo M, et al. [Occupational exposure to vibration and Dupuytren's disease: a case-controlled study]. Med Lav. 1987 Sep-Oct;78(5):386-92.

24. Palmer KT, D'Angelo S, Syddall H, et al. Dupuytren's contracture and occupational exposure to hand-transmitted vibration. Occup Environ Med. 2014 Apr;71(4):241-5.

25. Descatha A, Bodin J, Ha C, et al. Heavy manual work, exposure to vibration and Dupuytren's disease? Results of a surveillance program for musculoskeletal disorders. Occup Environ Med 2012;69:296-9

26. Lucas G, Brichet A, Roquelaure Y, et al. Dupuytren's disease: personal factors and occupational exposure. Am J Ind Med 2008;51:9-15

27. Thomas PR, Clarke D. Vibration white finger and Dupuytren's contracture: are they related? Occup Med 1992;42:155-8

28. Chanut JC. [DUPUYTREN'S DISEASE. RETRACTION OF THE PALMAR APONEUROSIS. A SERIES OF 378 CASES OBSERVED IN A LARGE PLANT]. Rev Rhum Mal Osteoartic 1964;31:24-8

\section{Figure 1. Flow-chart of the included studies}

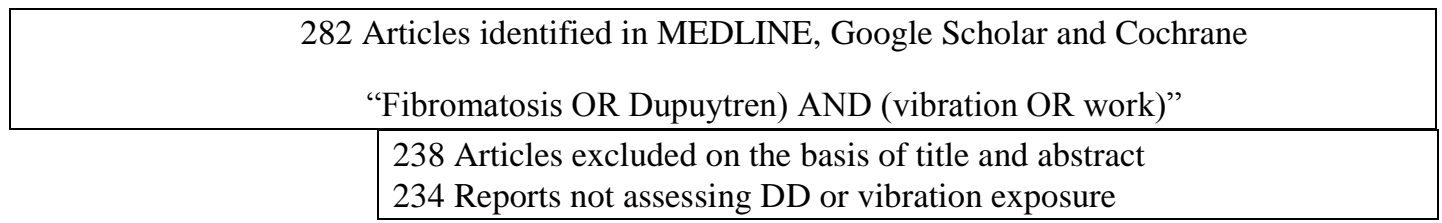




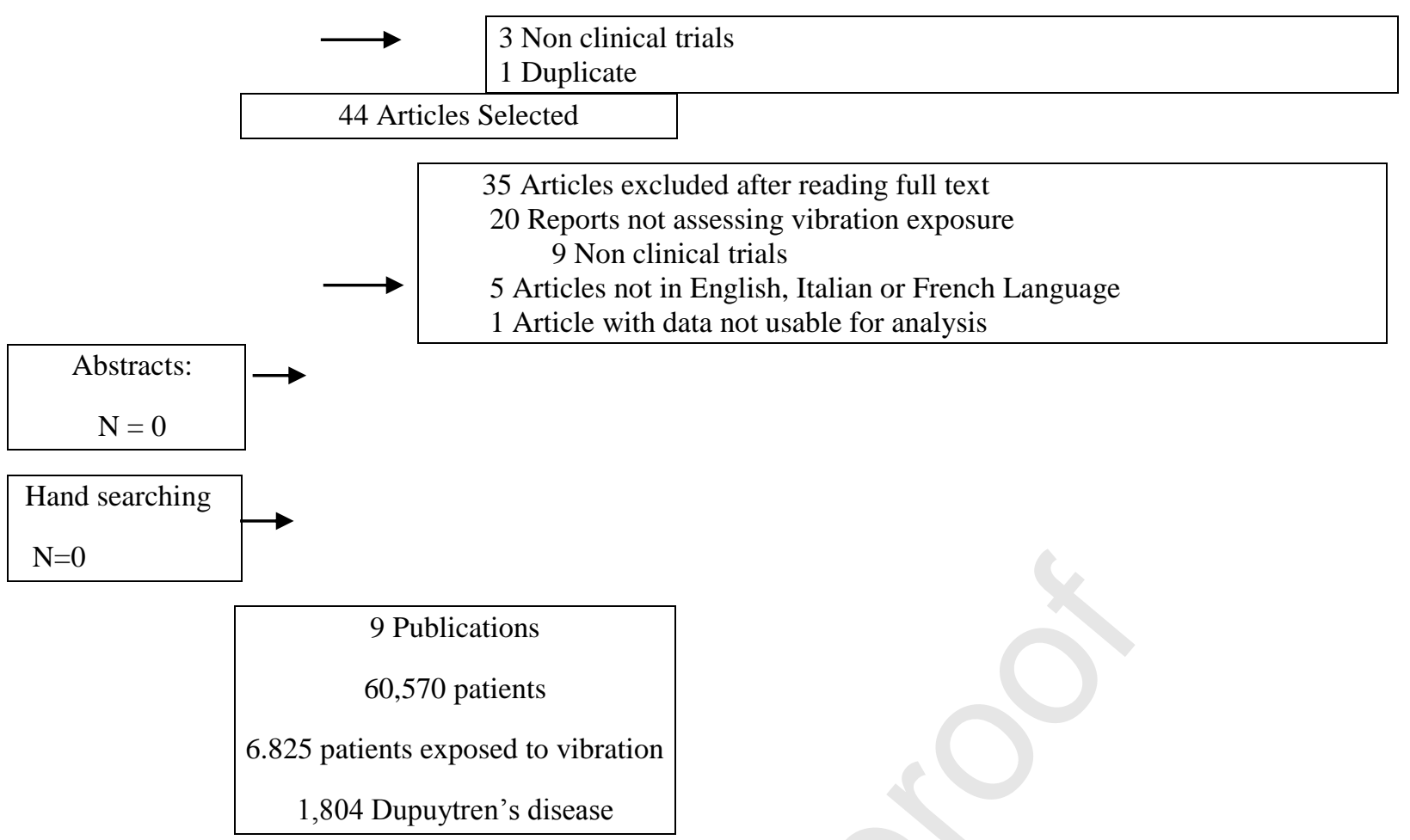

Figure. 2. Comparison of Dupuytren's Disease risk depending to vibration exposure

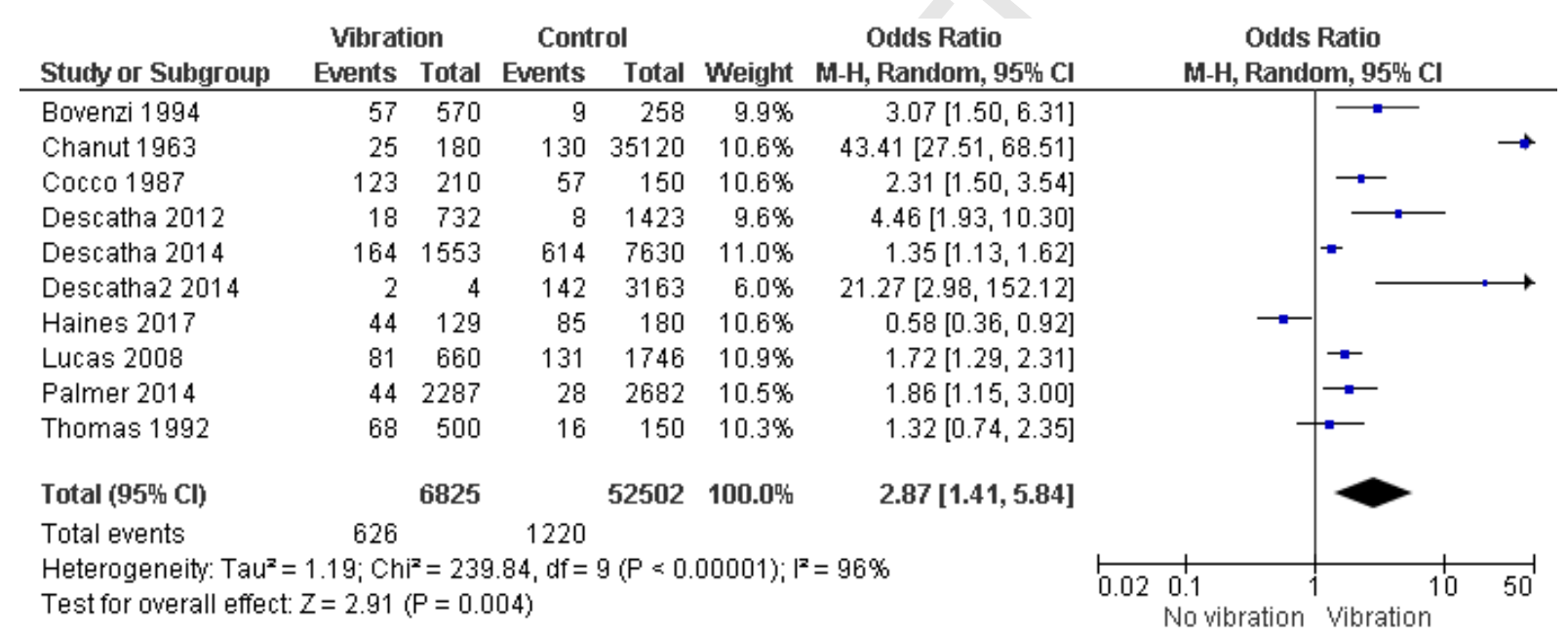


Figure 3. Meta-regression

\begin{tabular}{|c|c|c|c|c|c|c|}
\hline Variables & $\begin{array}{c}\text { Number of } \\
\text { studies included }\end{array}$ & $\begin{array}{c}\text { I- } \\
\text { squared }\end{array}$ & & & Coefficient $(95 \% \mathrm{Cl})$ & $\begin{array}{c}\mathrm{p}- \\
\text { value }\end{array}$ \\
\hline Age, years & 16 & $0.0 \%$ & $-\infty$ & & $-0.25 \quad(-2.60,2.10)$ & .403 \\
\hline Sex, Male as reference & 7 & $0.0 \%$ & & -O工 & $0.06 \quad(-0.16,0.28)$ & .525 \\
\hline Diabetes, \% & 5 & $0.0 \%$ & & $\longrightarrow$ & $0.11 \quad(-0.09,0.31)$ & .190 \\
\hline Alcohol, \% & 5 & $0.0 \%$ & - & - & $-0.001(-0.07,0.07)$ & .943 \\
\hline Smoking, \% & insufficient data & & & & & \\
\hline Sample size, $n$ & 7 & $0.0 \%$ & & i & $0.000 \quad(-0.00,0.00)$ & .944 \\
\hline
\end{tabular}


Table 1. Characteristics of the included publications

\begin{tabular}{|c|c|c|}
\hline References & Information & $\begin{array}{r}\text { Population } \\
\text { N total N Vibration N DD }\end{array}$ \\
\hline $\begin{array}{l}\text { Haines et al. } \\
\text { Am J Ind Med 2017;60:724- } \\
733 \text { [11] }\end{array}$ & & 309129129 \\
\hline $\begin{array}{l}\text { Descatha et al. } \\
\text { BMJ Open } 2014 ; 29 \text { :e004214 } \\
\text { [12] }\end{array}$ & $\begin{array}{l}2 \text { different cohorts } \\
\text { in the same study: } \\
\text { one for male and } \\
\text { one for female }\end{array}$ & $\begin{array}{l}100171553496 \\
35704160\end{array}$ \\
\hline $\begin{array}{l}\text { Palmer et al. } \\
\text { Occup Environ Med } \\
2014 ; 71: 241-5 \text { [24] }\end{array}$ & & 4969228772 \\
\hline $\begin{array}{l}\text { Descatha et al. Occup Environ } \\
\text { Med 2012;69:296-9 [25] }\end{array}$ & & 216173227 \\
\hline $\begin{array}{l}\text { Lucas et al. } \\
\text { Am J Ind Med 2008;51:9-15 } \\
{[26]}\end{array}$ & & 2406660212 \\
\hline $\begin{array}{l}\text { Bovenzi M. } \\
\text { Occup Environ Med } \\
1994 ; 51: 603-11[13]\end{array}$ & & 82857066 \\
\hline $\begin{array}{l}\text { Thomas et al. Occup Med } \\
\text { 1992;42:155-8 [27] }\end{array}$ & & 65050084 \\
\hline $\begin{array}{l}\text { Cocco et al. Med Lav } \\
\text { 1987;78:386-92 [23] }\end{array}$ & 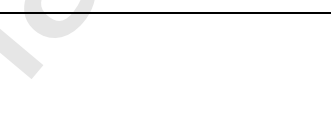 & 360210180 \\
\hline $\begin{array}{l}\text { Chanut JC. Rev Rhum Mal } \\
\text { Osteoartic 1964;31:24-8 [28] }\end{array}$ & & 35300180378 \\
\hline
\end{tabular}

